\title{
Animation Augmented Reality Book Model (AAR Book Model) to Enhance Teamwork
}

\author{
Wannaporn Chujitarom ${ }^{1} \&$ Pallop Piriyasurawong ${ }^{2}$ \\ ${ }^{1}$ Faculty of Digital Art, Rangsit University, Patumthani, Thailand \\ ${ }^{2}$ King Mongkut's University of Technology North Bangkok, Thailand \\ Correspondence: Wannaporn Chujitarom, Faculty of Digital Art, Rangsit University, Patumthani, 12000, Thailand. \\ Tel: 6-687-555-9392. E-mail: wannaporn.c@rsu.ac.th
}

Received: February 12, $2017 \quad$ Accepted: March 20, $2017 \quad$ Online Published: June 27, 2017
doi:10.5539/ies.v10n7p59

\begin{abstract}
This study aims to synthesize an Animation Augmented Reality Book Model (AAR Book Model) to enhance teamwork and to assess the AAR Book Model to enhance teamwork. Samples are five specialists that consist of one animation specialist, two communication and information technology specialists, and two teaching model design specialists, selected by purposive sampling. The instrument used in the study was an evaluation form for the Book Model. Statistics used in the study were arithmetic mean and standard deviation. The result shows that: an AAR Book Model to enhance teamwork achieved contains four components. Firstly, requirement analysis to create animation augmented reality; including 1) Objective setting, 2) Content analysis, 3) Student analysis, 4) Environment Analysis, 5) Teacher analysis, and 6) Creating animation augmented reality as a teaching material to motivate students. Secondly, teaching method: 1) Using gamification to motivate learning and practice; 2) Assigning students to work in teams and make a presentation. Thirdly, evaluating teamwork, conducted via teachers' observation and creating an integrated scoring rubric. Lastly, analysis of feedback: All five specialists agreed that the AAR Book Model to enhance teamwork developed through this study has a highest level of suitability $(\overline{\mathrm{x}}=4.75$, S.D. $=0.04)$.
\end{abstract}

Keywords: teamwork, gamification, animation, augmented reality

\section{Introduction}

Education today needs to change. Students have to learn how to live in the 21st century; otherwise they will be left behind. Modern education has to focus on the application of the knowledge, instead of studying the contents (Panit, 2013). This research sets out to demonstrate ways in which animation augmented reality and gamification can motivate student learning and also enhance teamwork. A derivative work comes first, which focuses on a self-analytic, result driven model for success.

The talents of 21 st century involves 3Rs $+8 \mathrm{Cs}$, Reading, Ritting, Reading, Ritting, Rithmetics, andCritical Thinking \& Problem Solving, Creativity \& Innovation, Collaboration, Teamwork \& Leadership, Cross-cultural Understanding, Communication, Information \& Media Literacy, Computing \& Media Literacy, Career \& Learning Self-reliance, Change, and in additional, +2Ls which is Learning Skills and Leadership (Panit, 2013).

In the exciting 21 st century, there are 4 kinds of challenges to come: 1) global dependence 2) an increasing number of democratic countries 3) a need for creative entrepreneurs and 4) importance in interpersonal relationships. Preparation for living is a significant thing. Students need to know how to work in team effective with others, as well as a creative way to handle conflicts, either in a traditional class or an online class. (Johnson \& Johnson 2011) Humankind is social animals which need to depend on each other, either directly or indirectly, such as generosity, collaboration, supporting, negotiation, arguing; this shows that humankind interacts and communicates with each other (Waew-ngam, 1991).

Teamwork occurs when 2 or more people who have the same goal work in the same direction to achieve the shared goal. (Waew-ngam, 1991; Nolan, 1997) ICT Literacy is one of the key skills to live in 21st century. (ETS, 2002; Panit, 2012) ICT proficiency consists of 7 steps: 1 . Define, able to use proper equipment for ICT; 2. Access, able to access ICT media; 3. Manage, able to handle the information, categorizing it into groups; 4. Integrate, able to understand, summarize, understand, and compare similarities and differences; 5 . Evaluate, able 
to reflect and assess the quality; 6. Create, able to establish new knowledge, adapts, apply, design, and reveals the information; and 7. Communicate, able to re-express information or knowledge to different kind (ETS, 2002).

Augmented Reality (AR) is a technology developed from the existing Virtual Reality technology by combining it with the real world, rendering a combined graphic of Virtual World and the real world via the camera, displayed in a computer screen or a projector. Graphics may vary, such as animated pictures with audio, 3D objects, etc. These are rendered by a computer program and displayed real-time. (Srifa, 2013; Meesuwan, 2014; Meesuwan, 2012; Proma-ngun, 2008; Furht, 2011) The first time Augmented Reality (AR) dated back in 1950 when Morton Heiling, a movie director, came up with an idea to make his audience experience his movies even more. In 1962, he invented a prototype out of his concept, which is described in "Cinema of the futher" as Sensorama. Later, Ivan Suntherland invented a headset in 1966 and two years after, 1968, he was the first person who invented augmented reality via headset vision. Later, Myron Krueger created a room with a video that a user can interact with virtual objects for the first time. (Boriwethanan, n.d.; Furht, 2011) Augmented Reality involves 3 processes (Meesuwan, 2013) which are 1. Image Analysis: starting by creating a database of pictures or markers, converting pictures recorded by the video camera into binary images; 2. Pose Estimation: it is a 3D calculation utilizing matrix to find the relationship between the distance the camera detects with a marker in database, compared, analyzed the data collected with the data recorded; 3. 3D Rendering: 3D graphics are rendered onto the pose estimation.

Gamification is how to apply gaming into what is not actually a game to motivate and promote learning, problem solving, or behaviors to comply with an objective in an effort to make it fun and engaging. Gamification use game mechanics to encourage learner to achieve goal, such as points, levels, competition, collaboration, rules, ranking board and time limited (KAPP, 2012; Association for Project Management,2014; Burk, 2014).

Animation originated from a Latin word, Animare, which means to make into life. Animation is made by means of the rapid display of a sequence of static images that minimally differ from each other. Animation techniques impress the audiences with image sequences in motion, generally either hand drawings or computer graphics. The human eye sees through persistence of vision and the images become animated continuously. This is called image persistence. The illusion - as in motion pictures in general — is thought to rely on the phenomenon (Lieser, 2010; Laowansiri, 1989). Benefits of animation in education are 1. It can display something human cannot demonstrate, 2. It can explain difficult thing more easily (Laowansiri, 1989).

The researcher sees the importance in improving teaching methods in the 21 st century which centralizes on the students, inspiring them to learn, and capable of working in teams. Students should be able to cooperate with their peers to achieve a lesson objective utilizing Animation Augmented Reality (AAR) and also gamification to motivate students to learn by themselves and to keep them interested throughout the lesson. This is developed in form of AAR Book Model to enhance teamwork. This instructional model was then evaluated by five specialists from three specific fields: one animation specialist, two teaching method design specialists and two communication and information technology specialists.

\section{Method}

The Method section describes in detail how the study was conducted, including conceptual and operational definitions of the variables used in the study, Different types of studies will rely on different methodologies; however, a complete description of the methods used enables the reader to evaluate the appropriateness of your methods and the reliability and the validity of your results, It also permits experienced investigators to replicate the study, If your manuscript is an update of an ongoing or earlier study and the method has been published in detail elsewhere, you may refer the reader to that source and simply give a brief synopsis of the method in this section.

\subsection{Objective}

1) Synthesize an Animation Augmented Reality Book Model (AAR Book Model) to enhance teamwork.

2) To assess the AAR Book Model to enhance teamwork.

\subsection{Methods}

The process of creating an AAR Book Model to enhance teamwork is divided into 8 steps as follows:

Literary review on related studies which includes: Augmented Reality (Srifa, 2013; Meesuwan, 2014; Meesuwan, 2012; Proma-ngun, 2008; Furht, 2011) Gamification (KAPP, 2012; Association for Project Management, 2014; Burk, 2014) and Animation (Lieser, 2010; Laowansiri, 1989) was conducted to create a framework for an AAR 
book Model. The strength of Animation is it can express learning content in enjoyable way. AR can attract an audience.

Primary Analysis, divided into 3parts:

1) Context Analysis: to analyze what type of context or environment is compatible with the model, such as the availability of tablets or smartphone and hi-speed internet network.

2) Student Analysis: to analyze which age of students is suitable with the model. Students are required to be able to use a tablet to interact with AAR. Students are also required to have primary knowledge of the subject.

3) Learning Analysis: to classify the contents into steps which are suitable for students of different age while there is conformity from basic lesson to advance lesson.

Synthesize an AAR Book Model to enhance teamwork.

Development of an AAR Book Model to enhance teamwork, focused on animation augmented reality to motivate the learner, for engage team activity.

Submitting the AAR Book Model to enhance teamwork to the advisor for checking and further advice.

Creating Research Instrument: Model Assessment Form using the Likert scale. The format of a typical five-level Likert item is: Strongly disagree, Disagree, Neither agree nor disagree, Agree, Strongly agree. And set interpretation criteria Suitability: 1.00-1.80 mean lowest, 1.81-2.60 mean low, 2.61-3.40 mean medium, 3.41-4.20 mean high and 4.21-5.00 mean highest.

Submitting the Model Assessment Form to the advisor and three experts to evaluate the conformity of the questions.

Model Assessment, conducted by five specialists, selected by purposive sampling. One animation specialist is famous animation director and university lecturer; Two teaching model design specialists are professor and doctor, both are university instructors and graduated from education field; And two communication and information technology specialists are Assistant Professor and ICT specialist at Center of Innovative Learning and also work as a university instructors. Assessment by Model Assessment Form using the Likert scale. The results were summarized afterwards.

\subsection{Framework}

Independent Variables are Instuctional Design, Gamification, Animation, Augmented Reality and Book.

Dependent Variables are AAR Book Model to enhance teamwork. (Figure 1)

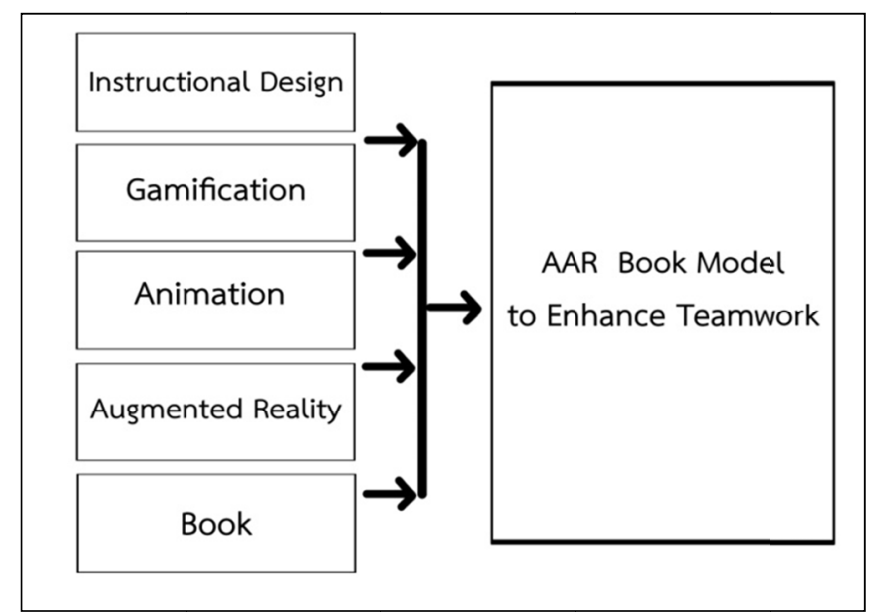

Figure 1. Framework

\section{Results}

\subsection{The Researcher Synthesized AAR Book Model to Enhance Teamwork into 4 Components}

The AAR Book Model to enhance teamwork was appropriate for creating an approach to making an animation augmented reality book which uses gamification for motivate students. The Model contains 4 components. 
Component one of the model is AAR. This activity regulates the learner, content and teacher. The analysis of the results is used to produce AAR which attracts and motivates the leaner, tablet or smartphone with hi-speed internet is also necessary for this process. Component two, Teaching Methods using Gamification to drive students to encourage activity. The third component is teamwork skill assessment. And the fourth component is analyzing feedback. The details are as follows:

Component 1 Requirement Analysis includes:

1) Objective setting to check whether students have achieved after a lesson.

2) Content Analysis to check whether the contents are compatible for making into Animation Augmented Reality.

3) Student Analysis; to analyze the age of students to see whether they are compatible with the model. Students are required to be able to use a PC tablet to interact with Animation Augmented Reality.

4) Environment Analysis to analyze the environment for its compatibility with the model, such as availability of tablets and hi-speed internet to use Animation Augmented Reality.

5) Teacher Analysis to check whether they are capable of making contents into Animation Augmented Reality.

6) Creating an Animation Augmented Reality to motivate.

Component 2 Teaching Methods are:

1) Knowledge Test, Using gamification to encourage learner to achieve goal done by flash cards, jigsaw puzzle and other materials as deemed appropriate. Rewards are given to be used in the next level. This gamification process enhance collaborative and teamwork skill of students.

2) Assigning students to work in teams of four and have the make a presentation to express their information to the others in compliance with ICT Proficiency (ETS, 2002). These processes also enhance teamwork skill.

Component 3 Authentic Assessment includes teamwork skill assessment done by teacher's observation, creating an integrated scoring rubric.

Component 4 is analyzing feedback from the students and improving the AAR Book Model to enhance teamwork. (Figure 2)

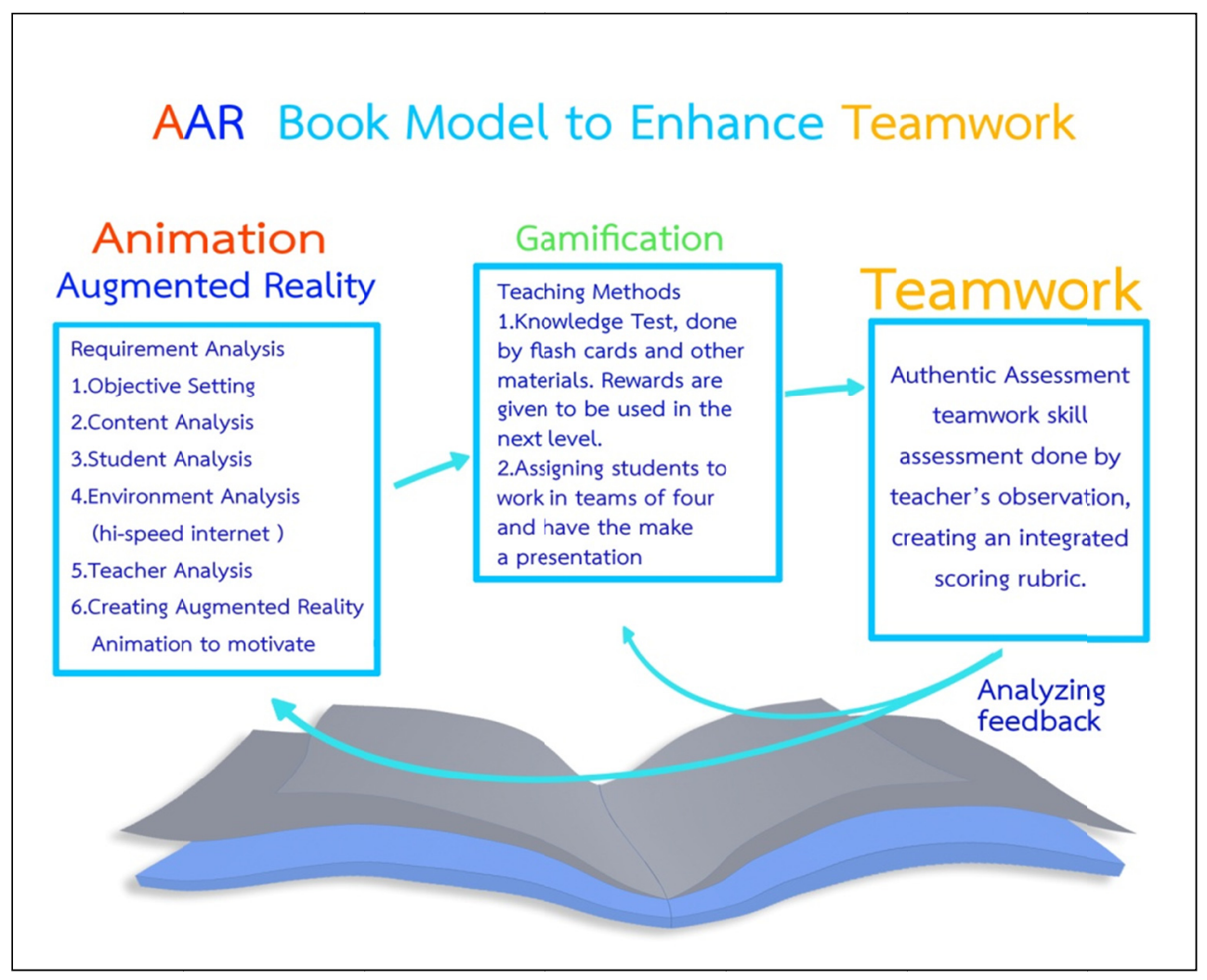

Figure 2. AAR Book Model to enhance teamwork 


\subsection{The Assessment Results of the AAR Book Model to Enhance Teamwork Are Shown in Table 1}

Interpretation Criteria Suitability: 1.00-1.80 mean lowest, 1.81-2.60 mean low, 2.61-3.40 mean medium, 3.41-4.20 mean high and 4.21-5.00 mean highest.

Table 1. Arithmetic mean and standard deviation results from 5 specialists

\begin{tabular}{lccc}
\hline Components & Evaluation $(\overline{\mathrm{x}})$ & standard deviation(S.D.) & Suitability \\
\hline $\begin{array}{l}\text { Component 1 Requirement Analysis } \\
\text { Component 2 }\end{array}$ & 4.7 & 0.54 & Highest \\
$\begin{array}{l}\text { Teaching Methods } \\
\text { Component 3 }\end{array}$ & 4.7 & 0.50 & Highest \\
$\begin{array}{l}\text { Authentic Assessment } \\
\text { Component 4 Analyzing feedback }\end{array}$ & 4.8 & 0.45 & Highest \\
\hline Results & 4.8 & 0.45 & Highest \\
\hline
\end{tabular}

The results of component 1 - 4 from five specialists showed that the AAR Book Model to Enhance Teamwork has a highest level of suitability. All five specialists are feedback about AAR is good for attractive learner, school or university have to provide a hi-speed internet, which is common for nowadays, and agreed that AAR and gamification can enhance teamwork skill of leaner.

\section{Discussion}

The AAR Book Model to enhance teamwork that utilizes animation, augmented reality and gamification can enhance teamwork, be separated into 4 components. The first component is the need analysis, which includes creating AAR that motivates the learner. All five specialists agreed that the developed instructional model was at the highest appropriate level. Results are according to a study of Kuchampu (2015) regarding a ubiquitous mobile web application with gamification for a course 'Effective Writing for Corporate Communication'. The study suggests that there are 3 steps: 1 . Pre-training preparation; 2. Mid-training preparation which consists of 2.1 in-class operations and 2.2 ubiquitous operations; 3 . Post-training. Media requirement survey suggests that there is a high requirement. Content assessment by specialists has a good result. Techniques in media making are good. Content-related tests to assess the quality of the survey are good. Post-training participants are higher than pre-training at a significant level of .05 and the satisfaction level of the samples is excellent, according to a study by Suphanpong Wongsipeng and Natthawee Utthakrit (Wongsipeng \& Utthakrit, 2012) regarding applying Virtual Reality into teaching Thai Alphabets, which divides the study into 4 aspects: 1 . Program functions, 2 . Contents and information, 3. User Interface and art, 4. System. Satisfaction level towards the system is excellent. It is also in compliance with a study by Danai Moungkeow (Moungkeow, 2005) regarding computer-aided teaching with animation for music study for Prathomsuksa 1 students. The results shows that the computer-aided teaching with animation has its effectiveness of 82.83/82. 59 and the competency of students taught by the computer-aided teaching is higher than students taught under traditional environment at a significant level of 0.01. It also complies with a study by Chubua, Wattananarong, and Phonlaptawee (2015) regarding the development of virtual peers to promote teamwork of students in developing ICT projects. The result shows that the virtual peers have an excellent satisfaction level. Students' competency is significantly 0.1 higher.

\section{Conclusions}

AAR Book Model to enhance teamwork focuses on motivating student to learn through Animation Augmented Reality and encourage teamwork with gamification, keeping students interested in lessons. There is also presentation-making in according to the ICT Proficiency (ETS, 2002). Authentic assessment is done by teacher's observation. Feedback then is taken into account to be analyzed and used to improve the AAR Book Model to enhance teamwork. For further work, the AAR Book Model to enhance teamwork can be applied into different subjects. Assessment by five specialists suggests that the AAR Book Model to enhance teamwork has a highest level of suitability. $(\overline{\mathrm{x}}=4.75$, S.D. $=0.04)$

\section{Acknowledgments}

The researcher would like to thank Assist. Prof. Dr. Pallop Piriyasurawong, who has given all useful advice.

\section{References}

Association for Project Management. (2014). Emerging trends Introduction to Gamification (p. 6). Buckinghamshire: apm. 
Boriwethanan, N. (n.d.). Augmented Reality When real world combined with virtual world.

Burke, B. (2014). Gamify: How gamification motivates people to do extraordinary things (p. 4). Brookline: Gartner, Inc.

Chubour, S., Wattananarong, K., \& Phunlaptawee, K. (2015). Development of a Virtual Teamwork System for Enhancing Students' Teamwork Abilities to Develop Information System Projects. Technical Education Journal King Mongkut's University of Technology North Bangkok, 6(2), 77-86.

ETS. (2002). Succeeding in the 21st Century What Higher Education Must Do to Address the Gap in Information and Communication Technology Proficiencies. Educational Testing Service.

Furht, B. (2011). Handbook of Augmented Reality. https://doi.org/10.1007/978-1-4614-0064-6

Johnson, D. W., \& Johnson, R .T. (2011). 21st Century Skills: Rethinking How Students Learn (pp. 305-306). Bangkok: Open worlds.

Kapp, K. M. (2012). The gamification of learning and instruction: Game-based methods and strategies for training and education (p. 10). San Francisco: Pfeiffer.

Kapp, K. M., BLAIR, L., \& MESCH, R. (2014). The gamification of learning and instruction Fieldbook (p. 55). San Francisco: Wiley.

Kuchampu, R. (2015). The Development of Ubiquitous Mobile Web Application by Gamification for Training under the subject of Effective Writing for Organizational Communication. A thesis presented to King Mongkut's University of Technology Thonburi of the requirements for the degree of Master of Science in Industrial Education Program in Learning Technology and Mass Communication.

Laowansiri, P. (1989). Advanced Film Production. SukhothaiThammathirat Open University Publishing.

LIESER, W. (2010). THE WORLD OF DIGITAL ART. Potsdam: h.f.ullman publishing.

Meesuwan, W. (2014). Design and development of learning technologies Augmented Reality, Julladit Printing, Phetchabun.

Meesuwan, W. (n.d.). Augmented Reality. Retrieved from http://www.edu.nu.ac.th/wiwatm/

Miller, C. H. (2014). Digital Storytelling a creator's guide to Interactive Entertainment. Burington: Focal Press.

Moungkeow, D. (2005). The effect of using a computer-assisted instruction with cartoon animation to teach music for prathom suksa 1 students. A thesis presented to Ramkhamhaeng University in partial fulfillment of the requirements for the degree of master of education.

Nolan, W. (1997). Teamwork. Se-education public company limited, Bangkok.

Panit, W. (2012). Learning into the 21st century (1st ed.). Bangkok: Siam Commercial Foundation.

Proma-ngun, W. (2012). In Virtual Reality Technology. Retrieved from http://www.docstoc.com/docs/28427384/ Virtual-Reality-Technology

Srifa, P. (2013). The idea of making Augmented Reality media (Augmented Reality: AR).

Vongsripeng, S., \& Utakrit, N. (2012). Applies Augmented Reality Techniques to use to teach Thai alphabet lessons. The Eight National Conference on Computing and Information Technology.

Waew-ngam, T. (1991). Group dynamics. Medsai Printing.

\section{Copyrights}

Copyright for this article is retained by the author(s), with first publication rights granted to the journal.

This is an open-access article distributed under the terms and conditions of the Creative Commons Attribution license (http://creativecommons.org/licenses/by/4.0/). 